\title{
Rooting Ability of Hardwood Cuttings in Highbush Blueberry (Vaccinium corymbosum L.) Using Different Indole-butyric Acid Concentrations
}

\author{
Haishan An ${ }^{1}$ \\ Forestry and Pomology Research Institute and Shanghai Key Lab of \\ Protected Horticultural Technology, Shanghai Academy of Agricultural \\ Sciences, No. 1000 Jinqi Road, Fengxian District, Shanghai 201403, P.R. \\ China
}

\section{Jiajia Meng ${ }^{1}$}

Shanghai Key Lab of Protected Horticultural Technology and Institute of Agro-food Standard and Testing Technology, Shanghai Academy of Agricultural Sciences, No. 1000 Jinqi Road, Fengxian District, Shanghai 201403, P.R. China

Fangjie Xu, Shuang Jiang, Xiaoqing Wang, Chunhui Shi, Boqiang Zhou, Jun Luo, and Xueying Zhang ${ }^{2}$

Forestry and Pomology Research Institute and Shanghai Key Lab of Protected Horticultural Technology, Shanghai Academy of Agricultural Sciences, No. 1000 Jinqi Road, Fengxian District, Shanghai 201403, P.R. China

Additional index words. Vaccinium corymbosum, hardwood cuttings, rooting response, position effect, indole-butyric acid concentration

\begin{abstract}
Vegetative propagation by cuttings is a very popular method. However, blueberry propagation using cuttings is still a main factor limiting its expansion because its results can vary according to the blueberry cultivar and environmental factors. This study aimed to evaluate the rooting abilities of hardwood cuttings for six blueberry cultivars (O'Neal, Misty, Diana, Biloxi, Bluebeauty, and Coville) using three different exogenous indolebutyric acid (IBA) concentrations $(1000,2000$, and $3000 \mathrm{ppm})$, and to determine if the cutting position (basal, central, apical) affects rooting performance. A control treatment (0 ppm IBA) was also performed. After 90 days of each treatment, rooting percentage, average root length, and average root number per cutting were assessed and used to calculate rooting index, which is a measure of rooting ability. The rooting percentages of hardwood cuttings differed largely among cultivars and were highest for 'Bluebeauty' $(68.55 \%)$, followed by 'Biloxi' $(\mathbf{6 8 . 0 1 \%})$. The rooting index values of these two cultivars (33.59 and 35.18, respectively) were significantly higher than those of the other four cultivars. The rooting response of blueberry hardwood cuttings to IBA concentrations was quadratic, and 1000 and $2000 \mathrm{ppm}$ IBA were sufficient to express the maximum rooting percentage in most cultivars. The rooting abilities of basal, central, and apical cuttings were similar with treatments with high IBA concentrations. The effects of the cultivar, IBA concentration, and interaction between them on rooting percentage, average root length, and average root number were significant; however, the effects of the cutting position on the rooting percentage and average root length were not. This suggested that the rooting abilities of blueberry hardwood cuttings were significantly influenced by the cultivar and IBA concentration rather than by the cutting position.
\end{abstract}

Blueberries (Vaccinium corymbosum L.) are becoming important commercial crops because of their healthy and flavorful properties, and they can be propagated by seeds,

Received for publication 23 Oct. 2018. Accepted for publication 19 Nov. 2018.

We thank the Key Scientific and Technological Project of Agricultural System in Shanghai for funding (No. 17391900800).

${ }^{1}$ These authors contributed equally to this work ${ }^{2}$ Corresponding author. E-mail: zhangxueying@saas. sh.cn. which result in a low rooting rate of cuttings of $\approx 30 \%$ to $35 \%$ (Braha and Rama, 2016). Therefore, the difficulty of blueberry propagation using cuttings is still a main factor limiting its expansion (Vignolo et al., 2012).

Numerous studies suggested that the rooting response of blueberry depends not only on the cultivar but also on the growing medium, collection time, and lignification of the cuttings (Hoffmann et al., 1995; Palanisamy and Kumar, 1997). For example, the rooting rates of 'Bluejay' and 'Bluegold' were $52.8 \%$ and $71.5 \%$, respectively, when the cuttings were planted in a peatmoss:sand $(4: 1 ; \mathrm{v} / \mathrm{v})$ medium, and 'Sharpblue' exhibited a $85.5 \%$ survival rate when cuttings were grown in a peatmoss medium; therefore, the rooting event was significantly improved when peatmoss was used as a major component of the media (Jeaboon et al., 2008). The best rooting result was achieved by semilignified cuttings sampled from the middle of the branch, and the most favorable substrate for blueberry cuttings was torf:perlite at 2:1 (v/v) (Braha and Rama, 2016). Moreover, it was suggested that the preferable period for cutting of blueberry was the stage between fruit harvesting and the onset of floral budding, which is from late June to early July in China; however, the highest rooting percentage of Ficus binnendijkii cuttings was obtained with 4000 to $6000 \mathrm{ppm}$ indole-butyric acid (IBA), and early September was the appropriate time for cutting (Babaie et al., 2014). To promote the rooting ability, the cuttings (either hardwood or softwood) were always treated with plant growth bioregulators such as IBA and naphthyl acetic acid (NAA); however, IBA was proven to be more effective than NAA for the rooting of cuttings (Naser et al., 2012; Singh and Khan, 2009).

Rooting abilities vary with cutting positions (Aishwath, 2006; Saifuddin et al., 2013). In general, cuttings from the distal end rooted better than those from the proximal end, which might be due to the higher endogenous auxin level at distal ends than at proximal ends (Palanisamy and Kumar, 1997). By assessing the effects of the cutting date and position (apical, basal, and central) on the rooting ability of Carignan (Vitis vinifera L.) shoots, Kraiem et al. (2010) revealed that both the rooting percentage and root weight exhibited positive correlations with the cutting position, whereas the root number varied with sampled positions. For blueberry, the rooting ability of green cuttings increased from the base toward the top of branches, and the highest rooting rate was achieved by cuttings from the center of branches (Braha and Rama, 2016). Unfortunately, data regarding how the cutting position of hardwood cuttings affects the rooting ability of blueberry in terms of rooting percentage, root length, and root number are scarce. Therefore, the present study aimed to analyze the rooting abilities of hardwood cuttings from six blueberry cultivars to evaluate the effects of exogenous IBA applications and cutting positions on adventitious root formation, and to determine the shallow root architecture, its cultivation requires sustainable environmental conditions such as $\mathrm{pH}$, soil moisture, and permeability, 
main effects and interactions among the cultivar, IBA, and cutting position on the rooting abilities of blueberry hardwood cuttings. The results obtained here might reveal the physiological traits that control adventitious root emergence and provide baseline data to improve blueberry propagation.

\section{Materials and Methods}

Plant materials and experimental design. Six blueberry cultivars were used in this study, including five southern highbush blueberry (O'Neal, Misty, Diana, Biloxi, and Bluebeauty) and one northern highbush blueberry (Coville). All materials were planted in a greenhouse located in Zhuanghang Comprehensive Experimental Station of Shanghai Academy of Agricultural Sciences in Shanghai, China. The experimental design was a randomized block with triplicates, and each replication comprised 50 cuttings. Before bud bursting (March), $\approx 150$ individual hardwood cuttings were randomly collected from each cultivar and divided into apical, basal, and central parts, and each was $10-15 \mathrm{~cm}$ in length. The cuttings were immersed for $1 \mathrm{~min}$ in deionized water (control) or 1000,2000 , or 3000 ppm IBA (dissolved in $600 \mathrm{~mL} \mathrm{75 \%} \mathrm{alcohol}$ and then diluted to $1 \mathrm{~L}$ with deionized water); then, they were inserted in the peatmoss:vermiculite:garden soil growing medium $(3: 1: 1 ; \mathrm{v} / \mathrm{v})$. The soil was fumigated with a high-temperature sterilizing oven to eliminate fungus. Before insertion of the cuttings, the growing medium was further sterilized with carbendazim; the $\mathrm{pH}$ of the medium was adjusted to 5.5. All treatments were performed on cutting seedbed in the greenhouse, and the cuttings were incubated using $90 \%$ to $95 \%$ relative humidity with a fog-spraying system (Xiao et al., 2014).
Determination of rooting phenotype. Approximately $12-13$ weeks (90 d) after insertion, the rooting percentage (RP), callus percentage (CP), average root length (ARL), and average root number (ARN) of each cutting were determined using the following formulas:

$$
\begin{array}{r}
\mathrm{RP}(\%)=(\text { number of rooted cuttings } / \\
\text { total number of cuttings }) \times 100
\end{array}
$$

$\mathrm{CP}(\%)=$ (number of cuttings with callus $/$ total number of cuttings) $\times 100$

Rooting ability was estimated based on rooting index $(\mathrm{RI}, \%)=\mathrm{RP} \times 50 \%$ + ARL $\times 25 \%+$ ARN $\times 25 \%$

Statistical analyses. All data were statistically analyzed using one-way analysis of variance (ANOVA) with SPSS 18.0 (SPSS Inc., Chicago, IL). Significant differences were compared using Duncan's multiple range tests, and $P \leq 0.05$ was considered significant. The main effects of the interactions between the cultivar, IBA concentration, and cutting position on RP, ARL, and ARN were analyzed by univariate regression using SPSS 18.0. All graphs were designed using GraphPad Prism 6.0 (GraphPad Software, Inc., La Jolla, CA).

\section{Results}

Rooting performance of hardwood cuttings among cultivars. The rooting performance of hardwood cuttings varied largely among blueberry cultivars. 'Biloxi' and 'Bluebeauty' showed the best rooting abilities, with RI values of 33.59 and 33.18, respectively, which were significantly higher than those of the other four cultivars (RI value range, 15.01 to 25.60 ) (Table 1). Generally, IBA application significantly affected the RP; with the exception of 'Bluebeauty', treatment with IBA (irrespective of concentration) significantly improved RP in relation to the control (Table 1). For 'O'Neal', for example, the RP of IBA-treated cuttings was 2-4-fold that of control cuttings (Table 1). On the contrary, $\mathrm{CP}$ was markedly reduced when IBA was applied (Table 1). The average root number per cutting was notably increased by applying IBA (Table 1), but ARL was not significantly affected by IBA treatments (Table 1). These results suggested that exogenous IBA might promote the formation of adventitious roots without influencing their average lengths.

Rooting response of hardwood cuttings to IBA concentrations. The rooting response of hardwood cuttings to IBA concentrations was quadratic. For 'O'Neal', 'Diana', 'Coville', and 'Biloxi', RP first decreased, then increased, and then decreased again with increasing IBA concentrations; the highest RP was obtained at $2000 \mathrm{ppm}$ IBA (Fig. 1; Supplemental Figs. 1, 3, 4, 5). The RP of 'Misty' seemed to increase continually with increasing IBA concentrations, and it reached its maximum with 3000 ppm IBA (Fig. 1). For 'Bluebeauty', IBA application exhibited an inhibitory effect on RP; it declined with increasing IBA concentrations, and the highest value was obtained at 1000 ppm (Fig. 1; Supplemental Figs. 2 and 6).

Rooting ability variation among basal, central, and apical cuttings. We further analyzed the effects of cutting positions on the rooting ability. The RPs of the basal, central, and apical parts of the cutting fluctuated widely among cultivars. For 'O'Neal', there were no significant differences in RPs among these three parts with an IBA concentration $\leq 2000 \mathrm{ppm}$, but that of the apical and

Table 1. Rooting performance of hardwood cuttings from six blueberry cultivars using different indole-butyric acid (IBA) treatments.

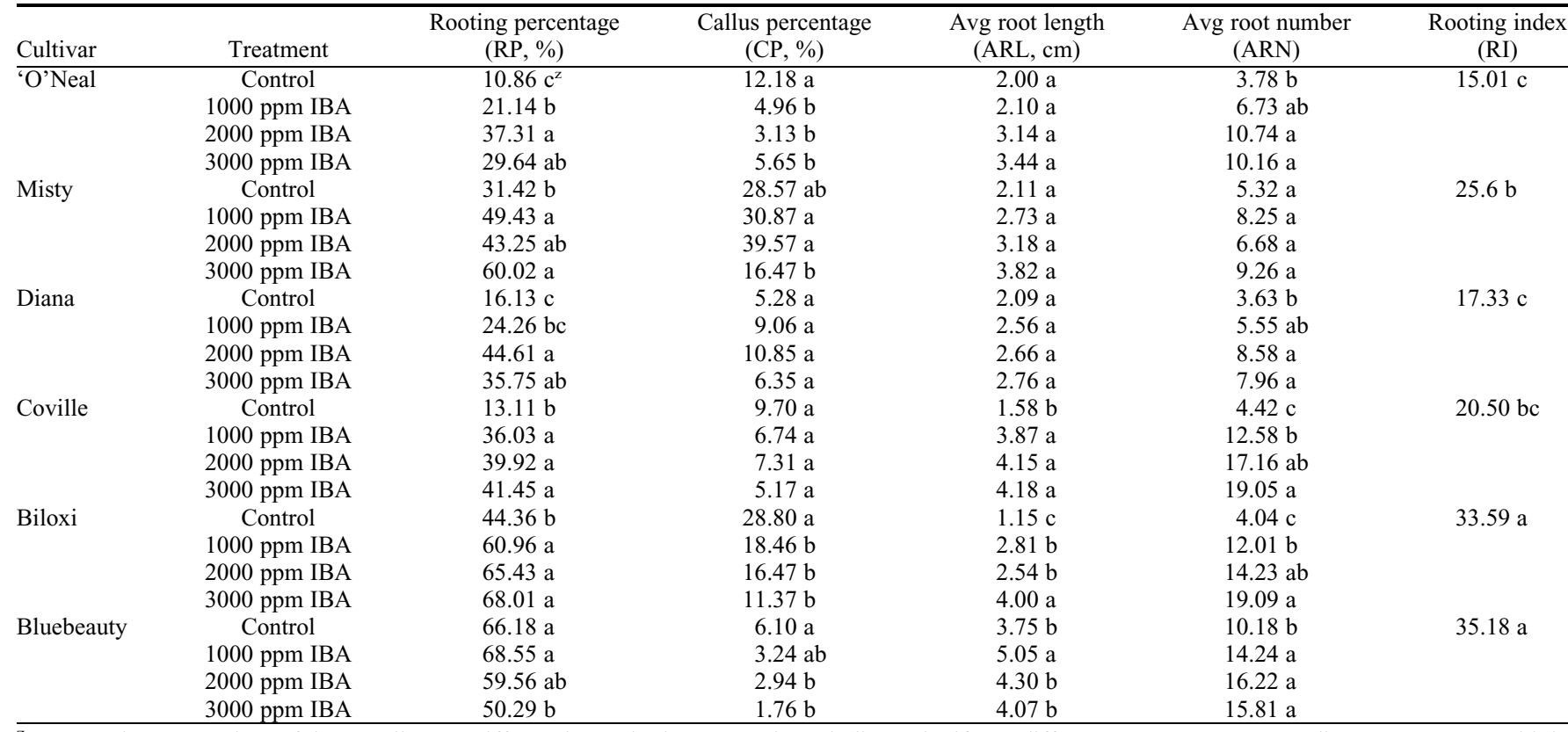

${ }_{\mathrm{z}}$ Data are the mean values of three replicates. Different letters in the same column indicate significant differences at $P \leq 0.05$ according to Duncan's multiple range tests. 

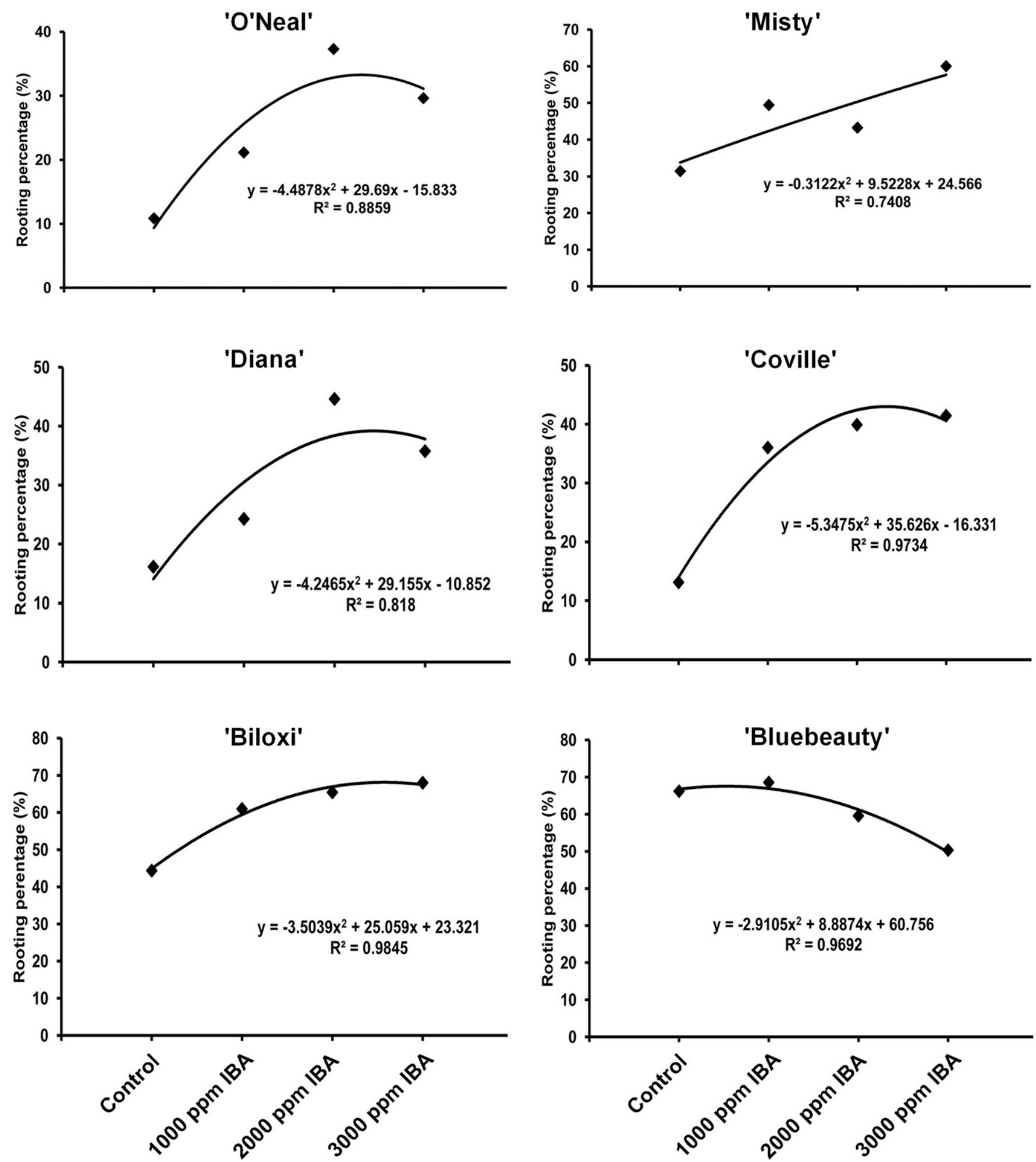

Fig. 1. Rooting responses of hardwood cuttings from six blueberry cultivars (indicated at the top of each graphic) to different indole-butyric acid (IBA) concentrations $(1000,2000$, or $3000 \mathrm{ppm})$. All data are the mean values of three replicates, and the curves were fitted by univariate regression using SPSS 18.0 .

central parts were significantly reduced with 3000 ppm IBA (Fig. 2). For 'Misty', the RP of the apical part was significantly reduced with IBA concentrations more than 2000 ppm, but there was no significant difference in the RPs of the different parts at lower IBA concentrations (Fig. 2). 'Diana' showed an opposite trend; the RPs of the basal cuttings were significantly higher than those of apical and central cuttings with the control and 1000 ppm IBA treatments. RPs were almost identical among the different parts using 2000 and 3000 ppm IBA (Fig. 2). For 'Coville', no significant differences in RPs were detected among the three parts using the same IBA treatment (Fig. 2). For 'Biloxi' and 'Bluebeauty', control and 1000 ppm IBA did not influence the RPs of the different parts of cuttings, but those of central and basal parts were significantly enhanced by higher IBA concentrations (i.e., 2000 and 3000 ppm) (Fig. 2).

The ARN of basal, central, and apical cuttings varied significantly with both cultivar and exogenous IBA concentrations. For 'O'Neal', the ARN of basal cuttings was significantly higher than that of apical 

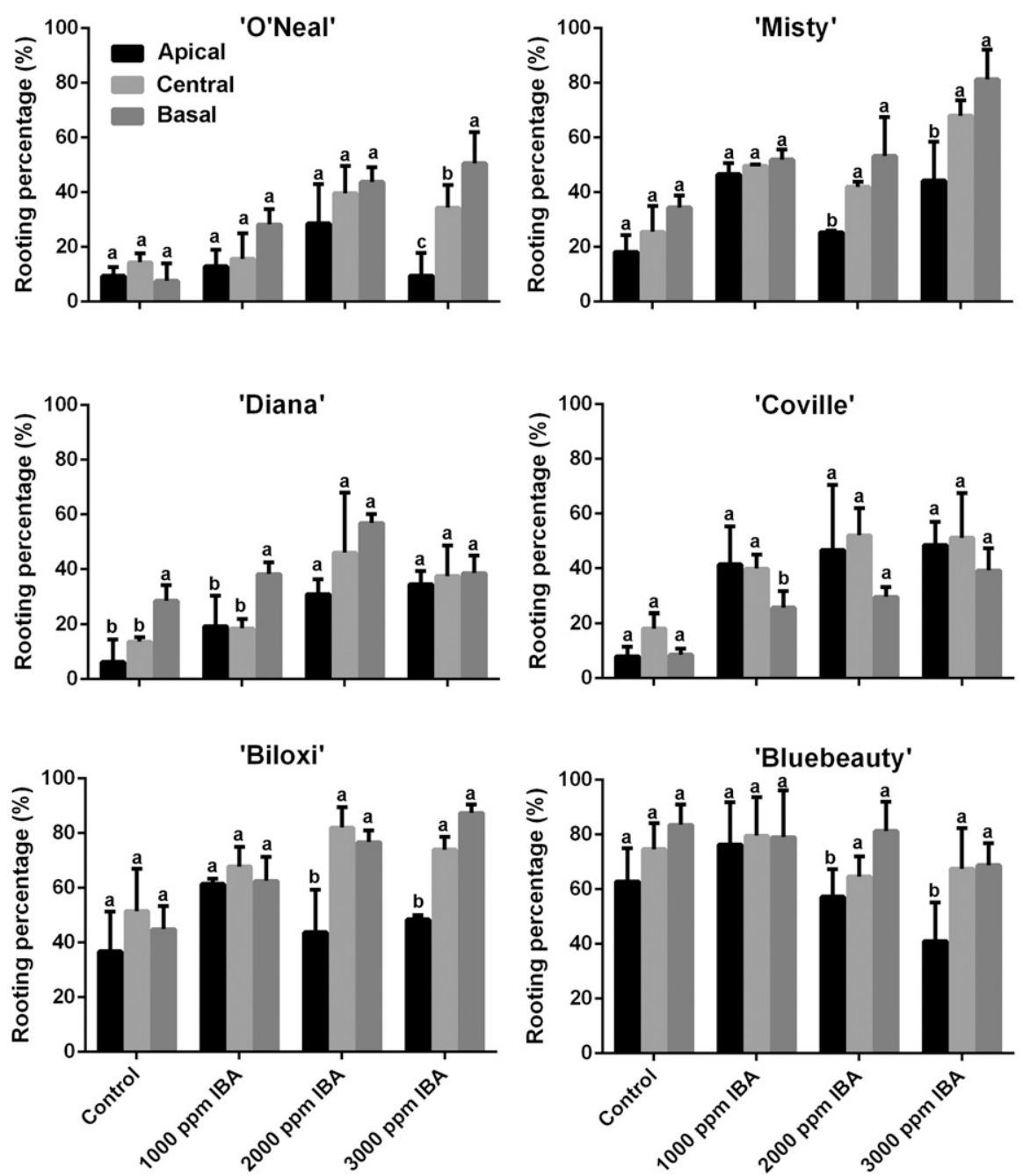

Fig. 2. The rooting percentages of hardwood cuttings taken from the basal, central, and apical parts of the stem of six blueberry cultivars (indicated at the top of each graphic) using different indole-butyric acid (IBA) concentrations $(1000,2000$, or $3000 \mathrm{ppm})$. All data are the mean values of three replicates, and the bar indicates the standard error. Different letters within the same treatment indicate significance at $P \leq 0.05$ according to Duncan's multiple range tests.

cuttings using control and 1000 ppm IBA treatments. Although there was no significant difference using 2000 ppm IBA, basal cuttings showed the highest ARN using 3000 ppm IBA, whereas the ARN of apical and central cuttings was significantly decreased using this IBA treatment (Fig. 3). This indicated that the rooting ability of apical and central cuttings was inhibited at high IBA concentrations. However, for 'Misty', 'Diana', and 'Coville', there were no significant differences in ARN using the same treatment (Fig. 3), indicating that the rooting abilities of these three cultivars were unaffected by the cutting position. For 'Biloxi', the ARN of basal cuttings was significantly reduced at $1000 \mathrm{ppm}$ IBA, but there were no significant differences with the other three treatments (Fig. 3). For 'Bluebeauty', the ARN of the apical position was reduced using the control and 2000 ppm IBA treatments, but there were no remarkable differences among the different parts using 1000 and 3000 ppm IBA (Fig. 3). Based on these results, the rooting abilities of the different parts seemed to depend on the cultivar and IBA concentration.
According to the ANOVA results, the effects of the cultivar, IBA concentration, and their interaction (cultivar $\times$ IBA concentration) on RP, ARL, and ARN were significant (Table 2), suggesting that the rooting abilities of blueberry hardwood cuttings were influenced by both the cultivar and IBA concentration. The cutting position significantly affected ARN (Table 2), and the interactions between the cultivar $\times$ cutting position and IBA concentration $\times$ cutting position significantly affected RP, but not ARL and ARN (Table 2). The triple interaction of cultivar $\times$ IBA concentration $\times$ cutting position was significant for ARL, but not for RP or ARN (Table 2). These results further indicated that the rooting abilities of blueberry hardwood cuttings were mainly affected by the cultivar and IBA concentration, rather than by the cutting position.

\section{Discussion}

Blueberry is difficult to root when propagated by stem cuttings because of its special root system, and because the emission of adventitious roots is influenced by multiple environmental factors such as hormones, nutritional substances in cuttings, plant age, season, and substrate condition, among others (Fischer et al., 2008; Rosier et al., 2004). In addition, the rooting ability depends not only on the cultivar but also on the cutting collection time, cutting position, or type of cutting tissue (Horigome et al., 2008). Therefore, in the present study, we compared the rooting abilities of the hardwood cuttings of six blueberry cultivars by analyzing rooting responses to different exogenous IBA concentrations and the effect of the position of the cutting on its rooting ability to find an effective method for blueberry expansion. Rooting abilities varied widely among cultivars, with RPs ranging from $10.86 \%$ to $68.55 \%$ (Table 1), which was in agreement with the previously suggested variations in RPs among blueberry hardwood cuttings from several cultivars $(46 \%$ to $59 \%)$ (Vignolo et al., 2012). The rooting ability involves the combined effects of RP, ARL, and ARN per cutting. Therefore, we further evaluated the rooting ability using the RI, which integrates RP, ARL, and ARN. Based on the RI, 'Biloxi' and 'Bluebeauty' exhibited better rooting performance than did the other four cultivars (Table 1). This might be mainly attributed to the heterogeneity in the genetic background of cultivars (Puri and Khara, 1992). However, the physiological status of the stem of the mother plant might have been very different, resulting in different rooting abilities; therefore, it is necessary to determine the conditions of cuttings, such as their levels of endogenous hormones or nutrients (Hamooh, 2014).

Rooting hormones are essential for producing quality roots; therefore, researchers always pretreat the stem cuttings with a plant growth regulator. Several studies have shown that IBA and NAA are effective for inducing the formation of adventitious roots (Naser et al., 2012; Singh and Khan, 2009). NAA could accelerate starch hydrolysis, thereby reducing sugars in cuttings and providing abundant energy and carbon sources for the generation of adventitious roots (Das et al., 1997). In many cases, the application of IBA to cuttings resulted in a more efficient induction of adventitious roots than NAA or indole acetic acid applications, because IBA can trigger or accelerate root primordial formation, which is the precondition for the emergence of adventitious roots (Aminah et al., 1995). In the present study, the RP of cuttings was remarkably improved, and the $\mathrm{CP}$ was notably reduced when treated with IBA (Table 1); however, the responses of cuttings to IBA concentrations varied largely among blueberry cultivars (Fig. 1). The response of RP to the IBA concentration was quadratic, and $1000 \mathrm{ppm}$ or $2000 \mathrm{ppm}$ IBA seemed to be more appropriate for obtaining the maximal RP for blueberry hardwood cutting (Table 1; Fig. 1; Supplemental Figs. 1-6). The rooting rate has been shown to decrease with increasing exogenous IBA 
concentrations (Hoffmann et al., 1995). Interestingly, the RPs of blueberry softwood cuttings also differed largely among cultivars, ranging from $57.76 \%$ to $83.23 \%$, and the effective IBA concentration for rooting in blueberry softwood cuttings was established at $1000 \mathrm{ppm}$ (Celik and Odabas, 2009). The mathematical modeling of IBA application for rooting in blueberry softwood cuttings further revealed that the most effective IBA concentrations for rooting and root growth were theoretically $641.69 \mathrm{ppm}$ and 712.75 ppm, respectively (Celik and Odabas 2009). However, 4000 ppm IBA proved to be most effective for hardwood cuttings of Jasminium grandiflorum (Nagraja et al., 1997), and 3000 ppm IBA was beneficial for hardwood cuttings of Malus xiaojinensis (Xiao et al., 2014) and Actinidia deliciosa (Gjeloshi et al., 2014), whereas 200 ppm IBA was the best treatment for inducing rooting in croton cuttings (Bharti et al., 2013). These discrepancies
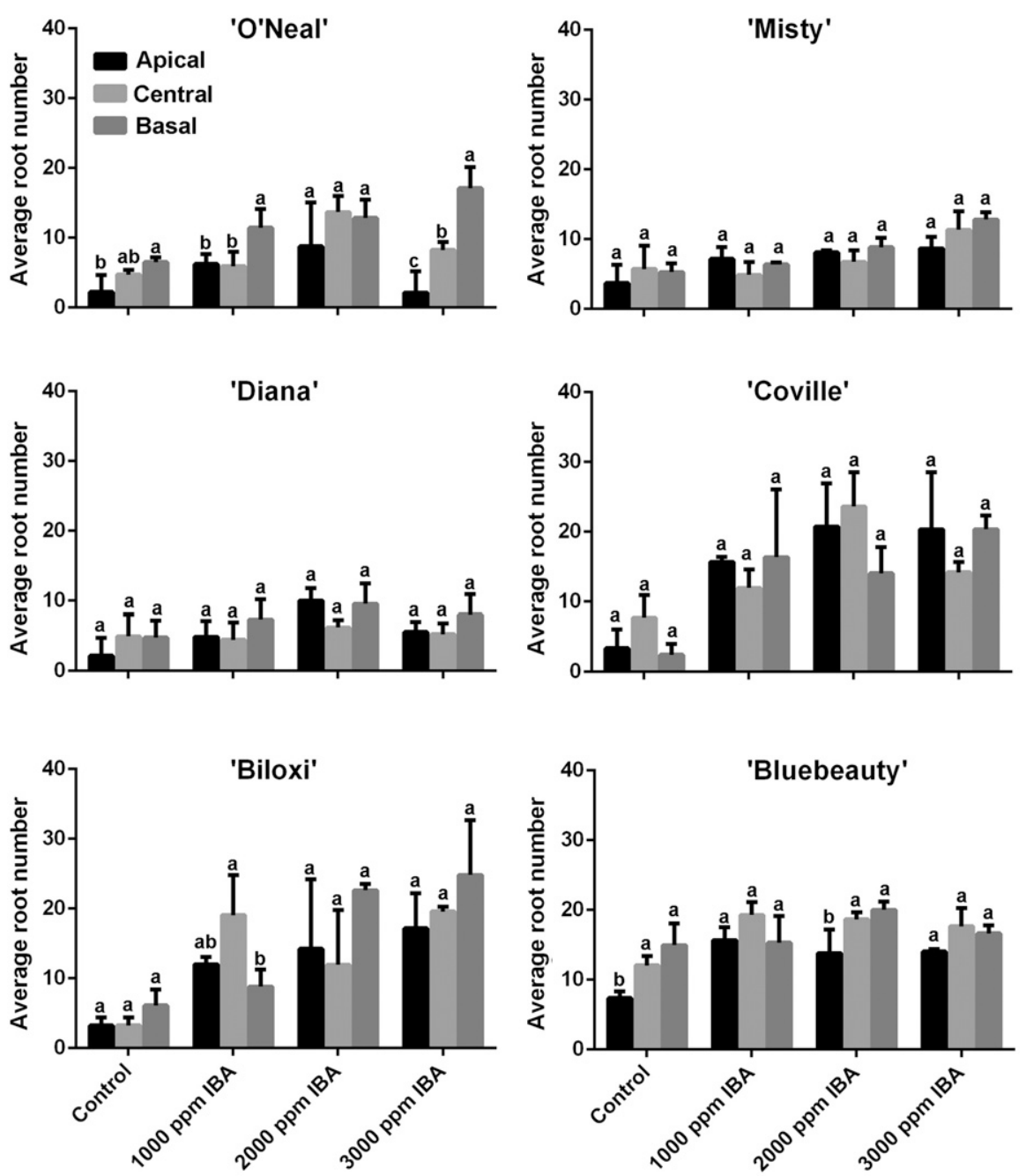

Fig. 3. Average root numbers produced by hardwood cuttings taken from the basal, central, and apical parts of the stem of six blueberry cultivars (indicated at the top of each graphic) using different indolebutyric acid (IBA) concentrations $(1000,2000$, or $3000 \mathrm{ppm})$. All data are the mean values of three replicates, and the bar indicates standard error. Different letters within the same treatment indicate significance at $P \leq 0.05$ according to Duncan's multiple range tests. indicated that the rooting response of cuttings to plant growth regulators varies among plant species, and that the mechanism by which cuttings respond to IBA and why IBA can initiate root primordial formation and regulate adventitious root emergence need to be further studied.

Traditionally, the apical and central parts of cuttings have been considered to have better rooting ability (Palanisamy and Kumar 1997). Our results showed no significant differences among the RPs of the apical, central, and basal parts of 'O'Neal', 'Misty', 'Biloxi', and 'Bluebeauty' cuttings when these were treated with 1000 ppm IBA or not treated (control); however, the RP of cuttings taken from the apical part of blueberry stems was significantly reduced by applying 2000 or 3000 ppm IBA (Fig. 2), which might be attributed to the inhibiting effects of high IBA concentrations. In addition, although the basal cuttings of 'Diana' showed a significantly higher RP than apical and central cuttings with the control and 1000 ppm IBA treatments, there were no significant differences among the three parts when the IBA concentration was $\geq 2000 \mathrm{ppm}$ (Fig. 2). This indicated that Diana was a hardrooting cultivar, and that IBA might mitigate the effects of the cutting position once its concentration was sufficient to induce rooting. Furthermore, there seemed to be no differences in ARN among the basal, central, and apical cuttings (Fig. 3). The effects of the cultivar, IBA concentration, cultivar $\times$ IBA concentration, cultivar $\times$ cutting position, and IBA concentration $\times$ cutting position on RP were significant (Table 2); however, the effects of the cutting position and cultivar $\times$ IBA concentration $\times$ cutting position were not significant, indicating that the blueberry RP is mainly influenced by the cultivar and IBA concentration rather than by the cutting position. Regarding the ARL, the effects of the cultivar, IBA concentration, cultivar $\times$ IBA concentration, and cultivar $\times$ IBA concentration $\times$ cutting position were significant, but the effects of the cutting position, cultivar $\times$ cutting position, and IBA concentration $\times$ cutting position were not (Table 2), revealing that the interaction between the cultivar and IBA concentration was most important for promoting root elongation. For ARN, the effects of the cultivar, IBA concentration, and cultivar $\times$ IBA concentration were also significant, whereas the cutting position, cultivar $\times$ cutting position, IBA concentration $\times$ cutting position, and cultivar $\times$ IBA concentration $\times$ cutting position were not (Table 2 ),

Table 2. Analysis of variance results for rooting percentage, average root length, and average root number.

\begin{tabular}{|c|c|c|c|c|c|c|c|c|c|c|}
\hline \multirow[b]{2}{*}{ Factor or interaction ${ }^{z}$} & \multirow[b]{2}{*}{$\mathrm{df}$} & \multicolumn{3}{|c|}{ Rooting percentage (\%) } & \multicolumn{3}{|c|}{ Average root length $(\mathrm{cm})$} & \multicolumn{3}{|c|}{ Average root number } \\
\hline & & MS & $\mathrm{F}$ & $P$ value & MS & $\mathrm{F}$ & $P$ value & MS & $\mathrm{F}$ & $P$ value \\
\hline$\overline{\text { Cultivar }}$ & 5 & $11,039.99$ & 7.32 & $0.00^{* *}$ & 25.97 & 6.33 & $0.005 * *$ & 469.33 & 6.23 & $0.002 * *$ \\
\hline IBA & 3 & $4,387.59$ & 3.53 & $0.04^{*}$ & 27.22 & 9.91 & $0.004 * *$ & 749.75 & 17.30 & $0.000 * *$ \\
\hline Position & 2 & $3,050.83$ & 3.62 & 0.06 & 1.302 & 1.12 & 0.442 & 161.35 & 5.19 & $0.048^{*}$ \\
\hline Cultivar $\times$ IBA & $1 \overline{5}$ & $1,044.89$ & 8.05 & $0.00 * *$ & 3.835 & 2.27 & $0.027^{*}$ & 54.86 & 2.87 & $0.007 * *$ \\
\hline Cultivar $\times$ position & 10 & 607.55 & 4.65 & $0.00 * *$ & 1.996 & 1.19 & 0.337 & 40.54 & 2.08 & 0.058 \\
\hline IBA $\times$ position & 6 & 414.11 & 3.03 & $0.02 *$ & 0.893 & 0.56 & 0.763 & 12.37 & 0.63 & 0.705 \\
\hline Cultivar $\times$ IBA $\times$ position & 30 & 129.32 & 0.64 & 0.93 & 1.693 & 1.55 & $0.043^{*}$ & 19.43 & 0.90 & 0.611 \\
\hline
\end{tabular}

${ }^{\mathrm{z}}$ The effects of the cultivar, IBA concentration, and cutting position on the rooting percentage, average root length, and average root number were analyzed using the univariate regression analysis in SPSS 18.0. **Significant difference at $P \leq 0.01$. $*$ Significant difference at $P \leq 0.05$. 
suggesting that ARN was also influenced by the cultivar and IBA concentration rather than the cutting position. Overall, these results suggested that the rooting ability might not be affected by the cutting position; instead, it may be mainly affected by the cultivar and IBA concentration.

\section{Conclusion}

The rooting abilities of hardwood cuttings varied significantly with blueberry cultivars, with Bluebeauty and Biloxi expressing the highest RPs (68.55\% and 68.01\%, respectively) and comprehensive RI values $(35.18 \%$ and $33.59 \%$, respectively). The rooting response of blueberry hardwood cuttings to exogenous IBA concentrations was quadratic, and 1000 or $2000 \mathrm{ppm}$ IBA effectively induced root formation and increased the root number in most blueberry cultivars. Cutting positions had no effects on RP, and interaction effects indicated that the rooting abilities of blueberry hardwood cuttings mainly depend on cultivar and exogenous IBA concentrations.

\section{Literature Cited}

Aishwath, O.P. 2006. Rooting potential of Indian bdellium (Commiphora wightii) cuttings taken from different shoot positions. Indian J. Hort. 63:319-323.

Aminah, H., J.M. Dick, R.R.B. Leakey, J. Grace, and R.I. Smith. 1995. Effect of indole butyric acid (IBA) on stem cuttings of Shorea leprosula. For. Ecol. Mgt. 72:199-206.

Babaie, H., H. Zarei, K. Nikde, and M.N. Firoozjai. 2014. Effect of different concentrations of IBA and time of taking cutting on rooting, growth and survival of Ficus binnendijkii 'Amstel Queen' cuttings. Not. Sci. Biol. 6:163-166.

Bharti, H., B.P. Singh, and K.P. Singh. 2013. Effect of variety, type of cutting and IBA concentration on rooting of croton (Codiaeum variegatum) cuttings. HortFlora Res. Spectr. 2:363-365.

Braha, S. and P. Rama. 2016. The effect of indol butyric acid and naphthalene acetic acid of adventitious root formation to green cuttings in blueberry cv. (Vaccinium corymbosum L.). Intl. J. Sci. Res. (Ahmedabad) 5:1-4.

Celik, H. and M.S. Odabas. 2009. Mathematical modeling of the indole-3-butyric acid application on rooting of northern highbush blueberry ( $\mathrm{Vac}$ cinium corymbosum L.) softwood-cuttings. Acta Physiol. Plant. 31:295-299.

Das, P., U.C. Basak, and A.B. Das. 1997. Metabolic changes during rooting in pre-girdled stem cuttings and air-layer of Heritiera. Bot. Bull. Acad. Sinica (Taipei) 38:91-95.

Debnath, S.C. 2007. Influence of indole-3-butyric acid and propagation method on growth and development of in vitro- and ex-vitro derived lowbush blueberry plants. Plant Growth Regulat. 51:245-253.

Fischer, D.L., G.K. Vignolo, and L.E.C. Antunes 2012. Rooting of blueberry hardwood cuttings as affected by wood type. Acta Hort. 926:273-278

Fischer, D.L.O., J.C. Fachinello, L.E.C. Antunes, Z.F.P. Tomaz, and C.L. Giacobbo. 2008. Effect of indole butyric acid and cultivar on rooting of hardwood cuttings of blueberry. Rev. Bras. Frutic. 30:285-289.

Fischer, D.L.O., G.W. Fernandes, E.A. Borges, C.F.B. Piana, and M.S. Pasa. 2016. Rooting of blueberry hardwood cuttings treated with indole butyric acid (IBA) and pro-rooting. Acta Hort. 1117:325-330.

Gjeloshi, G., T. Thomai, and E. Susaj. 2014. Effect of indole-3-butyric acid (IBA) $3000 \mathrm{ppm}$ on rooting ability and vegetative growth of the vegetative cuttings of Kiwifruit. Intl. Interdisciplinary Res. J. 4:98-102.

Hamooh, B.T. 2014. The effect of cutting collection time, auxin types and auxin concentrations on rooting of olive Olea europaea L. cuttings under arid land conditions. Intl. J. Engine. Res. Tech. 3:1389-1396.

Hoffmann, A., J.C. Fachinello, and A.M.D. Santos. 1995. Rabbiteye blueberry (Vaccinium ashei Reade) propagation by cuttings. Pes. Agro. Brasil. 30:231-236.

Horigome, M., T. Araki, T. Okada, M. Hatakeyama, and I. Kenmochi. 2008. Effect of hardwood cottage on the propagation of blueberry (Vaccinium). Bull. Gunma Agri. Tech. Cent. 5:33-39.

Jeaboon, J., L. Byoungyil, K. Hwayeong, K. Hakki, and S.J. Hong. 2008. Growth and survival rate of softwood cutting influenced by bed media, cutting length and thickness on several cultivars of highbush blueberry. Korean J. Hort. Sci. Tech. 26:134-138.

Kraiem, Z., W. Aidi, A. Zairi, and B. Ezzili. 2010 Effect of cutting date and position on rooting ability and fatty composition of Carignan (Vitis vinifera L.) shoot. Scientia Hort. 125:146-150.
Marino, S.R., J.G. Williamson, and J.W. Olmstead. 2014. Vegetative growth of three southern highbush blueberry cultivars obtained from micropropagation and softwood cuttings in two Florida locations. HortScience 49:556561.

Nag, S., K. Saha, and M. Choudhuri. 2001. A role of auxin and polyamines in adventitious roo formation in relation to changes in compounds involved in rooting. J. Plant Growth Regul. 20:182-194.

Nagraja, G.S., B.G. Muthapparai, and T.R. Guruprasad. 1997. Effect of intermittent mist and growth regulator on propagation of Jasminium grandiflorum by different types of cuttings. Haryana J. Hort. Sci. 20:183-188.

Naser, N., H. Davood, K. Behzad, and Z. Mohammad 2012. Improvement of rooting in semi-hardwood nandinadomestica stem cuttings as influenced by exogenous IBA and NAA auxins. Res. J. Biotechnol. 7:98-101.

Palanisamy, K. and P. Kumar. 1997. Effect of position, size of cuttings and environmental factors on adventitious rooting in neem ( $\mathrm{Aza}$ dirachta indica A. Jusss). For. Ecol. Mgt. 98:277-280.

Puri, S. and A. Khara. 1992. Influence of maturity and physiological status of woody cuttings: Limits and promises to ensure successful cloning. Indian For. 18:560-572.

Rosier, C., J. Frampton, B. Goldfarb, F.A. Blazich, and F.C. Wise. 2004. Growth stage, auxin type, and concentration, influence rooting of Virginia Pine stem cuttings. HortScience 39:13921396.

Saifuddin, M., N. Osman, and M.M. Rahman 2013. Influence of different cutting positions and rooting hormones on root initiation and root-soil matrix of two tree species. Intl. J. Agr. Biol. 15:427-434.

Singh, A. and M.A. Khan. 2009. Comparative effects of IAA, IBA and NAA on rooting of hardwood stem cuttings of Celtis australis Linn. Range Mgt. Agrofor. 30:78-80.

Vignolo, G.K., D.L.D.O. Fischer, V.F. Araujo, R.J. Kunde, and L.E.C. Antunes. 2012. Rooting of hardwood cuttings of three blueberry cultivars with different concentrations of IBA. Cienc. Rural 42:795-800.

Xiao, Z.F., N. Ji, X.Z. Zhang, Y.Z. Zhang, Y. Wang, T. Wu, X.F. Xu, and Z.H. Han. 2014 The lose of juvenility elicits adventitious rooting recalcitrance in apple rootstocks. Plant Cell Tiss. Org. 119:51-63. 

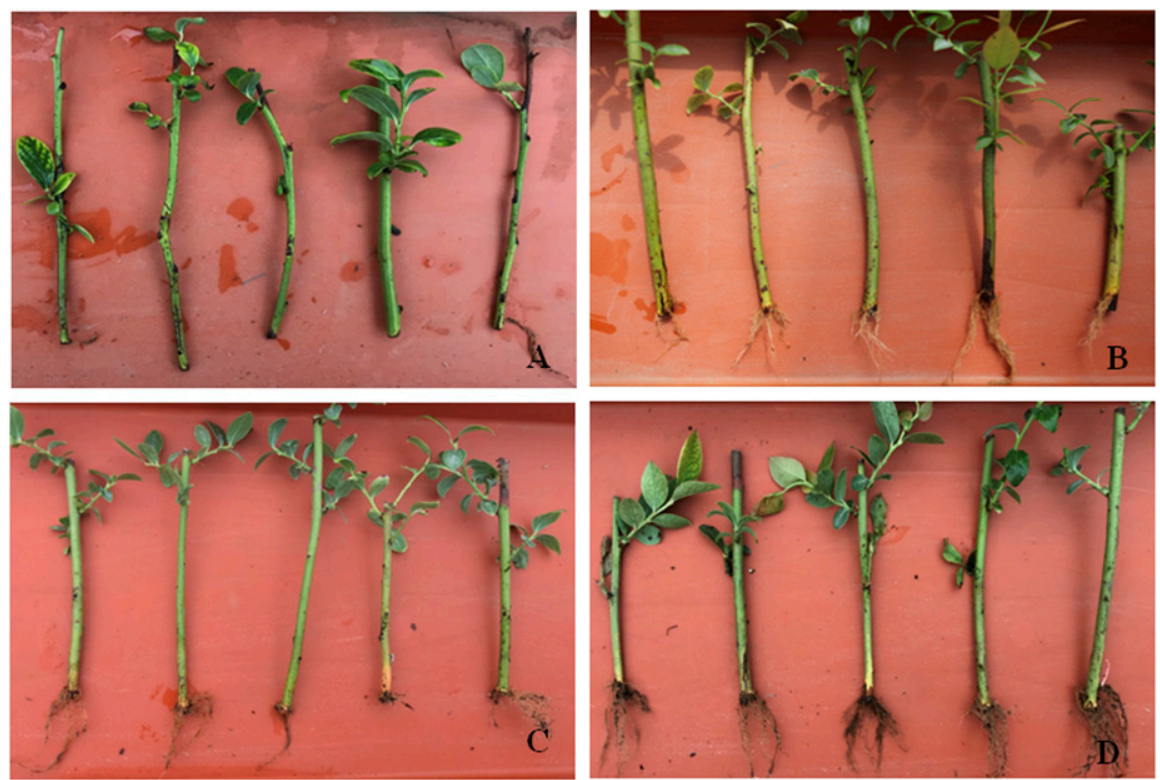

Supplemental Fig. 1. Rooting phenotype of the hardwood cuttings of blueberry cultivar 'O'Neal' treated with deionized water (control; A) and 1000 (B), 2000 (C), and 3000 (D) ppm IBA.
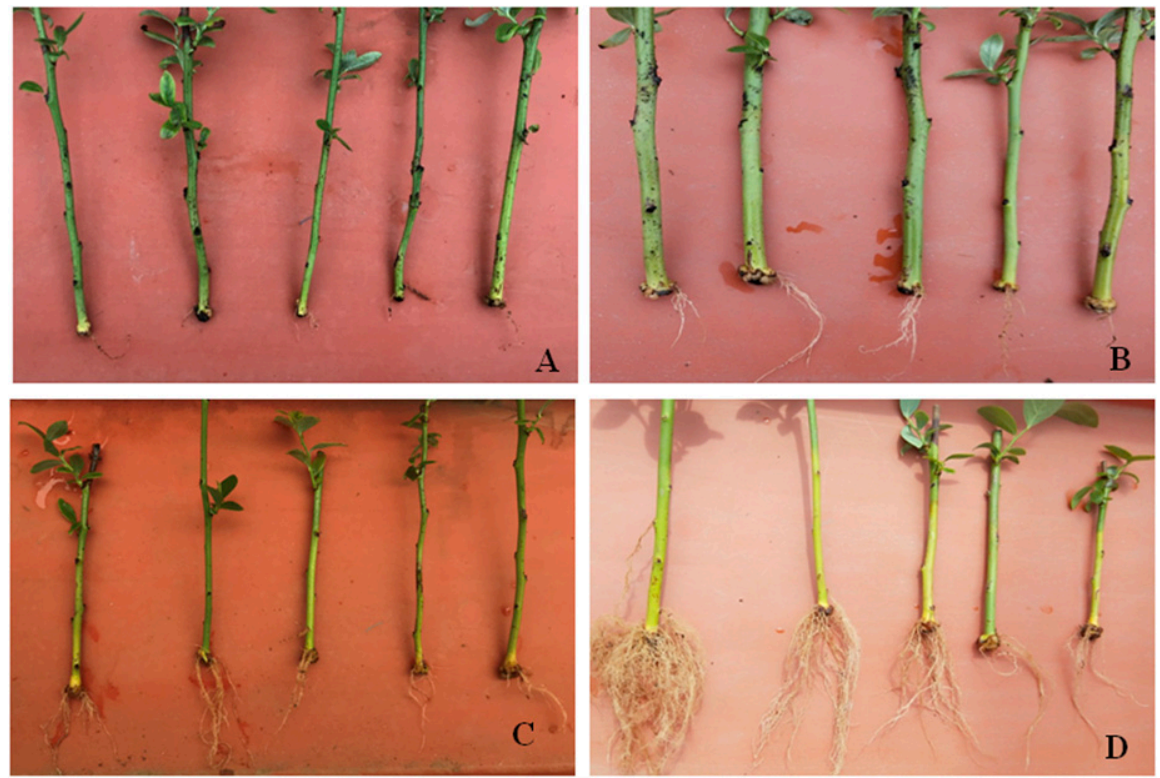

Supplemental Fig. 2. Rooting phenotype of the hardwood cuttings of blueberry cultivar 'Misty' treated with deionized water (control; A) and 1000 (B), 2000 (C), and 3000 (D) ppm IBA. 

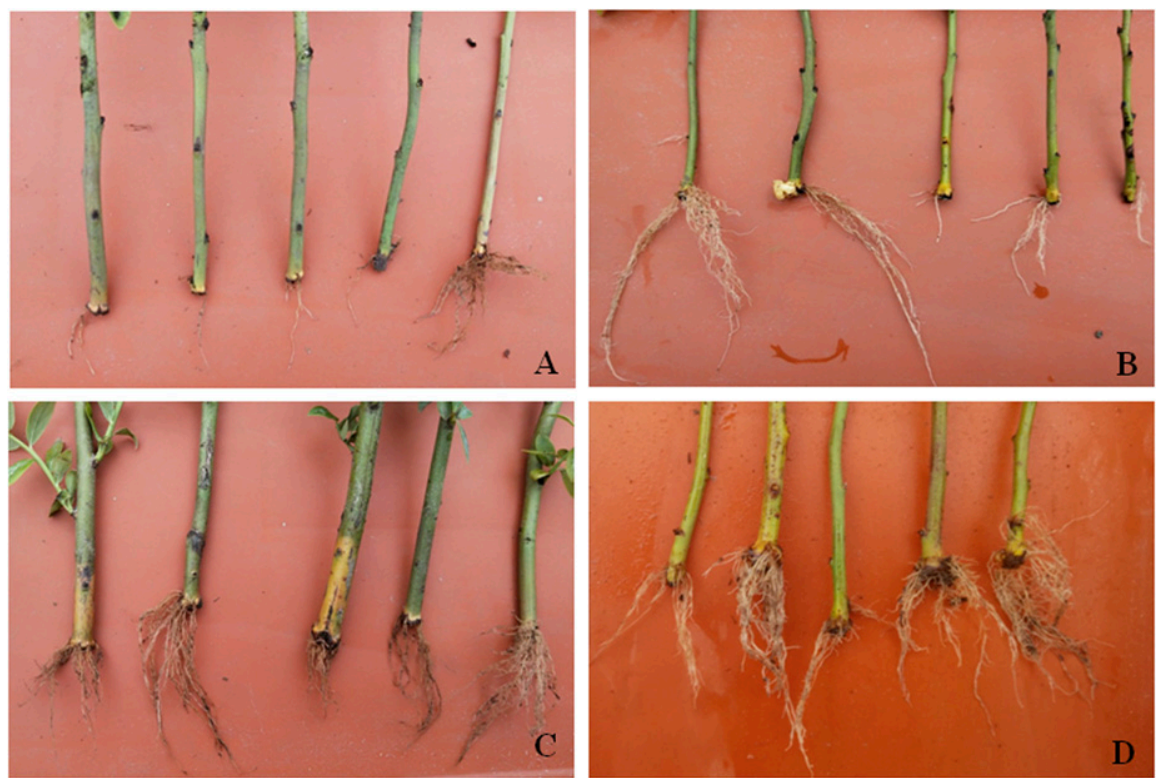

Supplemental Fig. 3. Rooting phenotype of the hardwood cuttings of blueberry cultivar 'Diana' treated with deionized water (control; A) and 1000 (B), 2000 (C), and 3000 (D) ppm IBA.
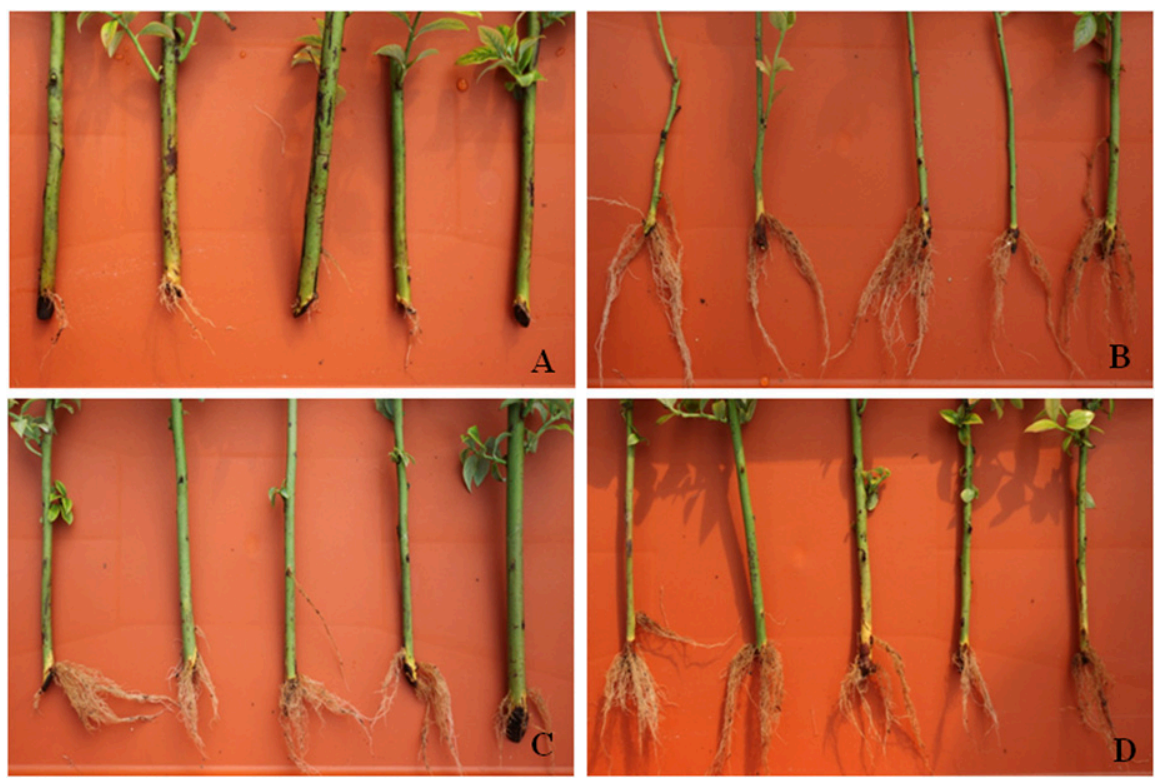

Supplemental Fig. 4. Rooting phenotype of the hardwood cuttings of blueberry cultivar 'Coville' treated with deionized water (control; A) and 1000 (B), 2000 (C), and 3000 (D) ppm IBA. 

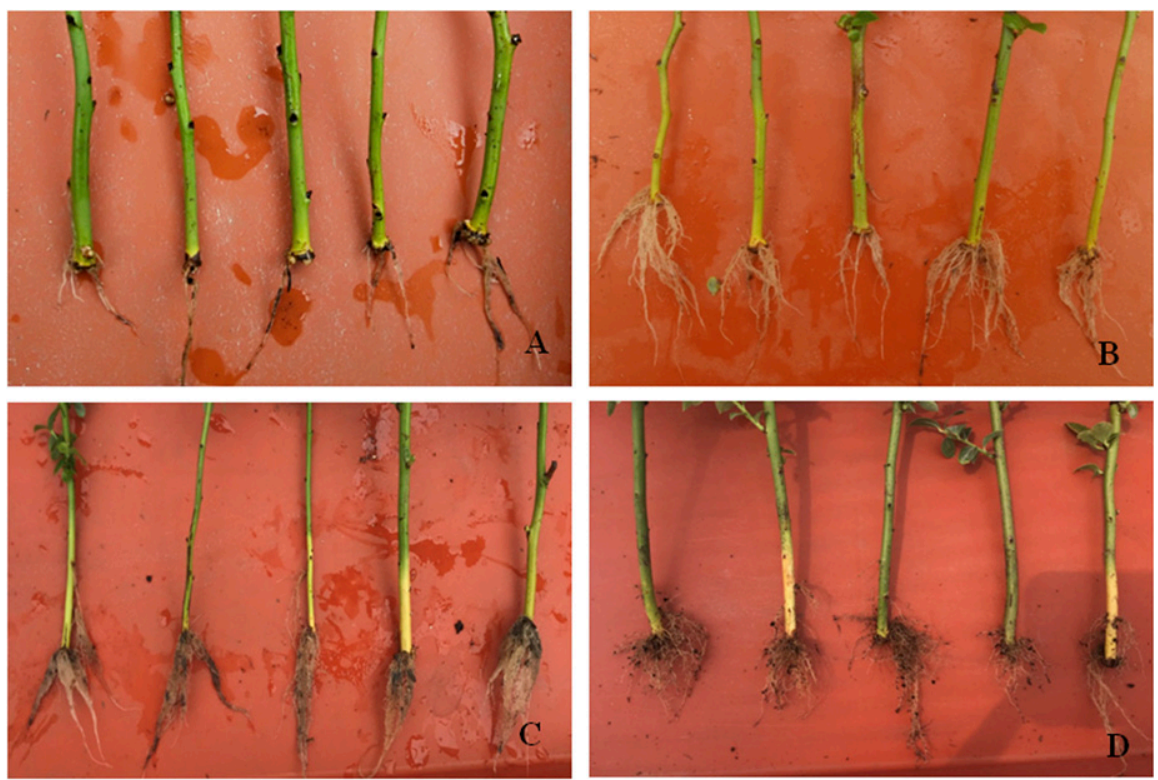

Supplemental Fig. 5. Rooting phenotype of the hardwood cuttings of blueberry cultivar 'Biloxi' treated with deionized water (control; A) and 1000 (B), 2000 (C), and 3000 (D) ppm IBA.
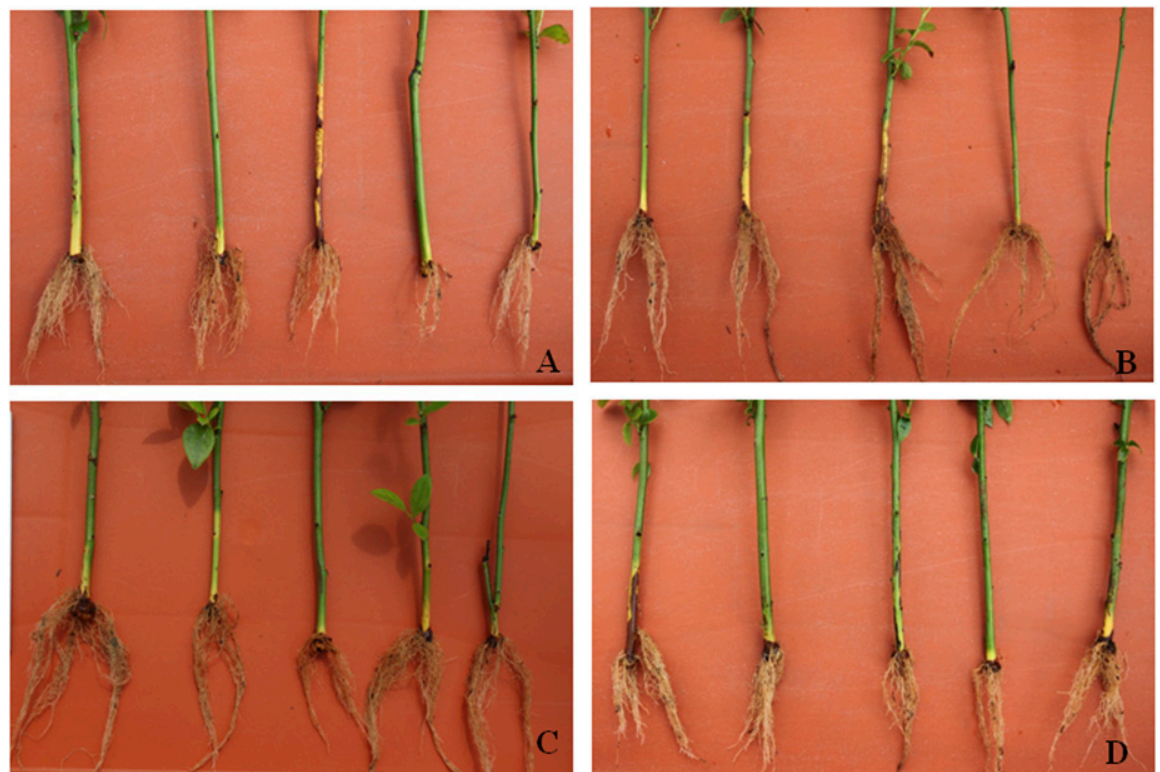

Supplemental Fig. 6. Rooting phenotype of the hardwood cuttings of blueberry cultivar 'Bluebeauty' treated with deionized water (control; A) and 1000 (B), 2000 (C), and 3000 (D) ppm IBA. 